Research Article

\title{
Depression, anxiety and stress levels among medical students in Mysore, Karnataka, India
}

\author{
Sunil D. Kumar*, Kavitha H.S., Praveen Kulkarni, Hugara Siddalingappa, Renuka Manjunath
}

Department of Community Medicine, JSS Medical College, Mysore, India

Received: 15 November 2015

Accepted: 18 December 2015

*Correspondence:

Dr. Sunil D. Kumar,

E-mail: sunilsclass@gmail.com

Copyright: (C) the author(s), publisher and licensee Medip Academy. This is an open-access article distributed under the terms of the Creative Commons Attribution Non-Commercial License, which permits unrestricted non-commercial use, distribution, and reproduction in any medium, provided the original work is properly cited.

\begin{abstract}
Background: Medical College is recognized as a stressful environment that often exerts a negative effect on the academic performance, physical health and psychological wellbeing of the student. The objective of the study was to assess the depression, anxiety and stress levels among the medical students by using DASS. To compare the depression, anxiety and stress levels among the medical students.

Methods: The cross sectional study was conducted in JSS medical college and Mysore Medical College of Mysore city. All the students studying in first year and final year MBBS who had spent more than six months in the medical college and willing to participate in the study were included. The Depression Anxiety Stress Scales (DASS), was used to assess the levels of depression, anxiety and stress among medical students.

Results: Among 332 students enrolled in the study, majority 213 (64.1\%) were in the age group of 17-20 years, 193 $(55.0 \%)$ were females and $215(64.8 \%)$ were studying in second term. The prevalence of depression, anxiety and stress were found to be $124(37.3 \%), 168(50.6 \%)$ and 109 (32.8\%) respectively. Most of the students were having mild degree of depression, anxiety and stress.

Conclusions: Prevalence of mental health problems like depression, anxiety and stress were more than $30 \%$ among medical students. As majority of the students were having milder degrees of illnesses they need to be addressed immediately before they manifest into severe forms.
\end{abstract}

Keywords: Depression, Anxiety, Stress, Medical students

\section{INTRODUCTION}

Mental disorders are often been neglected because of its non-specificity in diagnosis, indefinite clinical presentations, long term and varied treatment, various myths and belief systems associated with social stigma. ${ }^{1}$ Around $20 \%$ of the world's children and adolescents have mental disorders or problems. ${ }^{2}$ Medical school is recognized as a stressful environment that often has a negative effect on students' academic performance, physical health, and psychosocial well-being. ${ }^{3}$ More than half of the medical undergraduate students were found to be affected by depression, anxiety and stress. ${ }^{4}$
Medical profession is one of the top professional courses chosen because of its esteemed place and financial security in the Indian society. The students usually experience the burden of vast syllabus, high level of competition, inability to cope with the high expectations of parents after joining the course. This creates stress in them which will have a negative impact on their mental health status leading to sleep deprivation, reduced concentration, lack of confidence in handling patients, loss of self-esteem, anxiety, depression, interpersonal conflict, substance abuse, suicidal attempts etc.

It becomes necessary for the students to have a good knowledge of mental health problems, their early symptoms, the most effective options for treatment and 
services when required. Therefore, it was considered to deal with the mental health issues of the medical students as early detection and intervention may help in preventing and minimizing the effects of distress and help the students to deliver the best comprehensive care to the patients in the future.

\section{METHODS}

Mysore, situated in southern part of Karnataka is believed to provide quality education. Mysore city has two eminent Medical colleges, one of which is a government college and the other is a private establishment. A cross sectional study was conducted in the medical colleges, JSS medical college and Mysore Medical College for a period of three months. After obtaining the Institutional Ethical Committee approval, the Dean of both medical colleges was met and permission was obtained to conduct the study among the medical students.

All the students studying in first year and final year MBBS who had spent more than six months in the medical college and willing to participate in the study were included in the study.The Depression Anxiety Stress Scales (DASS) by Lovibond and Lovibond, a 42-item self-reported measure was used to assess depression, anxiety and stress. Items on the DASS are rated on 4point Likert - type, ranging from 0 (Did not apply to me at all) to 3 (Applied to me very much, or most of the time). Each of the three scales contains 14 items, divided into subscales of 2-5 items with similar content. The depression scale assesses dysphoria, hopelessness, devaluation of life, self-deprecation, lack of interest/involvement, and inertia. The Anxiety scale assesses autonomic arousal, skeletal muscle effects, situational anxiety, and subjective experience of anxious affect. The Stress scale (items) is sensitive to levels of chronic non-specific arousal. It assesses difficulty relaxing, nervous arousal, and being easily upset/agitated, irritable/over-reactive and impatient. Respondents are asked to use 4-point severity/frequency scales to rate the extent to which they have experience each state over the past week. The DASS has been found to be a reliable and valid method for assessing client changes in depressive mood and anxiety

All the students who gave verbal consent for the study were assembled in a class room, briefing was done about the study and the questionnaire was distributed and a time period of ten minutes was given to fill the questionnaire. Details regarding socio-demographic characteristics were also collected.

\section{RESULTS}

The study included 332 medical students, 163 from government medical college and 169 from private medical college. Majority $219(66 \%)$ were in the age group of 17-20 years and $195(58.7 \%)$ were females, 215 $(64.8 \%)$ were in first year (Table 1). The prevalence of depression, anxiety and stress among the medical students was $37.6 \%, 52.1 \%$ and $33.7 \%$ respectively. Both in depression and anxiety traits, majority of students were in moderate stage $(36.8 \%$ and $39.3 \%)$, whereas in stress, majority $(47.1 \%)$ of students were in mild stage (Table 2).

Table 1: Socio demographic characteristics of study participants $(n=332)$.

\begin{tabular}{|llll|}
\hline Character & Category & Number & Percentage \\
\hline Age group & $17-20$ & 219 & 66 \\
(years) & $>20$ & 113 & 34 \\
\hline \multirow{2}{*}{ Sex } & Boys & 137 & 41.3 \\
& Girls & 195 & 58.7 \\
\hline Term of & Second & 215 & 64.8 \\
study & Eighth & 117 & 35.2 \\
\hline
\end{tabular}

Table 2: Distribution of study participants based on severity of the psychological traits.

\begin{tabular}{|lllllllll|} 
& Mild & & Moderate & \multicolumn{3}{c|}{ Severe } & \multicolumn{3}{c|}{ Extremely severe } \\
& Number & $\%$ & Number & $\%$ & Number & $\%$ & Number & $\%$ \\
\hline $\begin{array}{l}\text { Depression } \\
\text { n-125 }(37.6 \%)\end{array}$ & 45 & 36 & 46 & 36.8 & 22 & 17.6 & 12 & 9.6 \\
\hline $\begin{array}{l}\text { Anxiety } \\
\text { n-173 }(52.1 \%)\end{array}$ & 40 & 22.8 & 69 & 39.3 & 37 & 21 & 27 & 15.3 \\
\hline $\begin{array}{l}\text { Stress } \\
\text { n-112 }(33.7 \%)\end{array}$ & 53 & 47.1 & 40 & 35.6 & 16 & 14.2 & 03 & 2.6 \\
\hline
\end{tabular}

Depression was seen significantly more among the students aged between 17 to 20 years $(65.6 \%)$ and more among girls $(59.2 \%)$. Majority of second term students $(64 \%)$ had depression when compared to eighth term students $(36 \%)$. Though anxiety was observed to be more among 17-20 years, girls and second term students, it was statistically not found significant. Stress was significantly more among girls $(66 \%)$ when compared to boys (Table 3). 
No difference was observed in the severity of anxiety and stress between the two age groups, sex and study term of medical students, expect for in the severity of depression where medical students aged more than 20 years, boys and eight term students had milder form of depression and medical students aged 17 to 20 years, girls and eighth term students had moderate form of depression (Table 4).

Table 3: Psychological traits in relation to socio-demographic profile.

\begin{tabular}{|c|c|c|c|c|c|c|c|c|c|c|c|c|}
\hline \multirow{3}{*}{$\begin{array}{l}\text { Psychological } \\
\text { traits }\end{array}$} & \multicolumn{4}{|l|}{ Age } & \multicolumn{4}{|l|}{ Sex } & \multicolumn{4}{|c|}{ Term } \\
\hline & \multicolumn{2}{|c|}{$17-20$ years } & \multicolumn{2}{|c|}{$>20$ years } & \multicolumn{2}{|c|}{ Boys } & \multicolumn{2}{|c|}{ Girls } & \multicolumn{2}{|c|}{ Second } & \multicolumn{2}{|c|}{ Eighth } \\
\hline & No & $\%$ & No & $\%$ & No & $\%$ & No & $\%$ & No & $\%$ & No & $\%$ \\
\hline $\begin{array}{l}\text { Depression } \\
n-125(37.6 \%)\end{array}$ & 82 & 65.6 & 43 & 34.4 & 51 & 40.8 & 74 & 59.2 & 80 & 64.0 & 45 & 36.0 \\
\hline p-value & 0.01 & & & & 0.01 & & & & 0.05 & & & \\
\hline $\begin{array}{l}\text { Anxiety } \\
n-173(52.1 \%)\end{array}$ & 121 & 69.9 & 52 & 30.1 & 66 & 38.1 & 107 & 85.6 & 118 & 68.2 & 55 & 31.8 \\
\hline p-value & 0.11 & & & & 0.22 & & & & 0.17 & & & \\
\hline $\begin{array}{l}\text { Stress } \\
\text { n-112 (33.7\%) }\end{array}$ & 75 & 37.0 & 37 & 33.0 & 38 & 33.9 & 74 & 66.0 & 16 & 14.2 & 03 & 2.6 \\
\hline p-value & 0.78 & & & & 0.05 & & & & 0.12 & & & \\
\hline
\end{tabular}

Table 4: Distribution of severity of psychological traits among medical students in relation to age, sex and their study term.

\begin{tabular}{|lllllll|}
\hline & Age & & Sex & & Term \\
\hline & 17-20 years & $>20$ years & Boys & Girls & Second & Eighth \\
\hline $\begin{array}{l}\text { Depression } \\
\text { n-125 }\end{array}$ & & & & & \\
Mild & & & & & \\
Moderate & $26(31.7 \%)$ & $19(44.1 \%)$ & $22(43.1 \%)$ & $23(31.0 \%)$ & $25(31.2 \%)$ & $20(44.4 \%)$ \\
Severe & $31(37.5 \%)$ & $15(34.8 \%)$ & $21(41.1 \%)$ & $25(33.7 \%)$ & $30(37.5 \%)$ & $16(35.5 \%)$ \\
Extremely severe & $17(20.5 \%)$ & $05(11.6 \%)$ & $05(09.8 \%)$ & $17(22.9 \%)$ & $17(21.2 \%)$ & $05(11.1 \%)$ \\
Total & $08(09.6 \%)$ & $04(09.2 \%)$ & $03(05.8 \%)$ & $09(12.1 \%)$ & $08(10.0 \%)$ & $04(08.8 \%)$ \\
\hline Anxiety & 82 & 43 & 51 & 74 & 80 & 45 \\
n-173 & & & & & \\
Mild & $29(23.9 \%)$ & $11(21.1 \%)$ & $15(22.7 \%)$ & $25(23.3 \%)$ & $27(22.8 \%)$ & $13(23.6 \%)$ \\
Moderate & $46(37.7 \%)$ & $23(44.1 \%)$ & $32(48.3 \%)$ & $37(34.4 \%)$ & $46(38.6 \%)$ & $23(41.6 \%)$ \\
Severe & $25(20.5 \%)$ & $12(23.0 \%)$ & $12(18.1 \%)$ & $25(23.2 \%)$ & $24(20.1 \%)$ & $13(23.5 \%)$ \\
Extremely severe & $21(17.2 \%)$ & $06(11.5 \%)$ & $07(10.5 \%)$ & $20(18.6 \%)$ & $21(17.6 \%)$ & $06(10.8 \%)$ \\
\hline Total & 121 & 52 & 66 & 107 & 118 & 55 \\
\hline Stress & & & & & \\
n-112 & & & & & \\
Mild & & & & & \\
Moderate & $36(47.9 \%)$ & $17(45.9 \%)$ & $21(55.2 \%)$ & $32(43.2 \%)$ & $36(48.6 \%)$ & $17(44.7 \%)$ \\
Severe & $26(34.6 \%)$ & $14(37.8 \%)$ & $15(39.4 \%)$ & $25(33.7 \%)$ & $25(33.7 \%)$ & $15(39.4 \%)$ \\
Extremely severe & $11(14.6 \%)$ & $05(13.5 \%)$ & $02(05.2 \%)$ & $14(18.9 \%)$ & $11(14.8 \%)$ & $05(13.1 \%)$ \\
\hline Total & $02(2.66 \%)$ & $01(02.7 \%)$ & $00(0.00 \%)$ & $03(4.05 \%)$ & $02(02.7 \%)$ & $01(02.6 \%)$ \\
\hline & 75 & 37 & 38 & 74 & 74 & 38 \\
\hline
\end{tabular}

\section{DISCUSSION}

Some degree of stress is helpful for individuals in meeting the new challenges, but persistently high and unrelieved stress can lead to psychological, physical and behavioral ill health. The prevalence of depression, anxiety and stress among the medical students of Mysore city, Karnataka is less when compared to the medical students in Bhubaneswar, Odisha. ${ }^{4}$ This may be an outcome of different cultural background, lifestyle, academic management. 
A study on 478 medical students in a private college of south Karnataka using the WHO SRQ 20 Questionnaire, observed $32.2 \%$ prevalence of mental distress, which is almost near to the present study (33.7\%). The highest level of stress was seen among girls, first year students and students aged 18 years which is similar to the study. ${ }^{5}$ A study in the neighbor state Kerala also shows higher depression scores in female students and anxiety scores were not significantly different in male and female students in both relaxed and stressed states which resembles the present study. ${ }^{6}$

The study showed high prevalence among second term students when compared to eight term medical students. As stated by Mandal et al the reasons for stress among second term students may be language problem, vast syllabus, fear of failure, parental and peer pressure, tight schedule, away from home, tough topics, substance abuse etc. ${ }^{7}$ Ruchi singh et al has expressed that eexaminations act as an unavoidable natural stressor and lead to increased stress, anxiety and depression in medical students. $^{8}$

The reasons may differ and the degree of illness may vary, but several observations have reported increasing levels depression, anxiety and stress among the medical students which should be addressed at the most. This will have a negative impact on the society as the patient care suffers.

\section{CONCLUSION}

The study reports above $30 \%$ prevalence of depression, anxiety and stress among medical students. Students' distress may influence professional development and adversely impact academic performance contributing to academic dishonesty and substance abuse, and may play a role in attrition from medical school. The need of the time is to make medical teachers and medical students aware of negative consequences of high levels of depression, anxiety and stress.

\section{Recommendations}

Educational institutes should adopt simple relaxation programmers for highly stressed students and provide support for their well examination period.

\section{Limitations}

The present study was based on results from a selfadministered questionnaire, hence reporting bias cannot be totally eliminated. This study was limited to one geographical area.
Funding: No funding sources

Conflict of interest: None declared

Ethical approval: The study was approved by the Institutional Ethics Committee

\section{REFERENCES}

1. Kishore J. National Health Programs of India, 11th edition. New Delhi: Century publications, 2014.

2. WHO. Fact file. 10 facts on mental health. http://www.who.int/features/factfiles/mental_health/ mental_health_facts/en/. Accessed on October, 2015.

3. Saravanan C, Wilks R. Medical Students' Experience of and Reaction to Stress: The Role of Depression and Anxiety. The Scientific World Journal. 2014;2014:1-8.

4. Iqbal S, Gupta S, Venkatarao E. Stress, anxiety \& depression among medical undergraduate students $\&$ their socio-demographic correlates. Indian J Med Res. 2015;141:354-7.

5. Asha B, Anusha R. Prevalence of mental distress among medical students of a private college in south Karnataka. International Journal of Basic and Applied Medical Sciences. 2015;5(2):164-8.

6. Roy PP, Sailesh KS, Doshi MA. Depression, anxiety and stress among first year undergraduate medical students. Asian Journal of Biomedical and Pharmaceutical Sciences. 2015;5(45):37-8.

7. Mandal A, Ghosh A, Sengupta G, Bera T, Das N, Mukherjee S. Factors affecting the performance of undergraduate medical students: A perspective. Indian Journal of Community Medicine. 2012;37(2):126-9.

8. Singh R, Goyal M, Tiwari S, Ghildiyal A. Effect of examination stress on mood, performance and cortisol levels in medical students. Indian J Physiol Pharmacol. 2012;56(1):48-55.

9. Dyrbye LN, Thomas MR, Shanafelt TD. Systematic review of depression, anxiety, and other indicators of psychological distress among U.S. and Canadian medical students. Acad Med. 2006;81:354-73.

10. Ghaderi AR, Venkatesh Kumar G, Kumar S. Depression, Anxiety and Stress among the Indian and Iranian Students. Journal of the Indian Academy of Applied Psychology. 2009;35(1):33-7.

Cite this article as: Kumar SD, Kavitha HS, Kulkarni P, Siddalingappa H, Manjunath R. Depression, anxiety and stress levels among medical students in Mysore, Karnataka, India. Int J Community Med Public Health 2016;3:359-62. 